\title{
Making Could Into Something We Can Sell
}

How do we, as environmental scientists, convince members of a public, who live in "today" and rightfully worry about putting food on the table, that climate issues are urgent and need immediate attention? Catastrophic events caused by natural hazards can be easier for people to act upon because of clearcut cause and effect (earthquake $\rightarrow$ tsunami $\rightarrow$ devastation $\rightarrow$ economic and human consequences). It didn't take long for many countries to come together to implement better tsunami warning systems after the 2004 Indonesian earthquake and tsunami. Coastal nations also worked to educate the public about what to do in the event of a tsunami. The behavioral modification required is small, and is only used infrequently.

Ocean and climate scientists don't have such an easy cause and effect to dangle before a skeptical public. What is the best way to explain to your neighbors that the carbon dioxide they put into the atmosphere by driving SUVs and keeping houses cool during the summer could ultimately mean that they (or their children) might not be able to put fish on the dinner table in 50 years? The relationship between atmospheric carbon dioxide and the myriad changes the excess gas will bring to ocean ecosystems is complex. Our scientific writing reveals that our understanding of the relationship is far from complete. Speaking scientist to scientist, we appropriately use qualified phrases, such as in this issue of Oceanography:

- "Decreased calcification could have negative impacts on marine ecosystems, with consequent effects on local marine fisheries and coastal protection from storms"

(Doney et al., p. 16).

- "Decreases in marine harvests due to ocean acidification thus could result in significant economic losses"

(Cooley et al., p. 172).

- "The uptake of anthropogenic $\mathrm{CO}_{2}$ by the global ocean induces fundamental changes in seawater chemistry that could have dramatic impacts on biological ecosystems in the upper ocean" (Feely et al., p. 36).

- "[Ocean acidification] could result in both changes in light quantity and spectral quality that could affect fundamental carbon fixation in the sea (Balch and Utgoff, p. 146).
The article by Tans (p. 26) is the rare exception that uses definitive language: "Despite the difficulty of long-term $\mathrm{CO}_{2}$ projections, some things are clear: fossil fuel burning has driven the $\mathrm{CO}_{2}$ increases thus far, the ocean will eventually take up the largest portion of the emissions, and the enhancement of $\mathrm{CO}_{2}$ in the atmosphere and ocean will last for a very long time."

But cautious scientific language can have the unintended consequence of leaving our neighbors uncertain as to what they should care about or whether anything needs to be done immediately. How do we help them connect the dots and demonstrate a clear cause and effect when we still have so many unanswered questions? We need to prevent the "coulds" from causing the public to assume that uncertainty about the full consequences of ocean acidification means they don't need to change their behaviors now. The battleground of public opinion is far removed from the seminar room, and groups opposing action on climate change use rhetoric skillfully, regardless of whether their "facts" can be backed up by good science. As just one example, the industry-backed group " $\mathrm{CO}_{2}$ is Green" is already running television ads attacking climate change legislation with claims that "This will cost us jobs...There is no scientific evidence that $\mathrm{CO}_{2}$ is a pollutant. In fact higher $\mathrm{CO}_{2}$ levels than we have today would help Earth's ecosystems." The " $\mathrm{CO}_{2}$ is Green" Web site (http://www.co2isgreen.org/) may drive us to distraction, but its clever use of language and marketing tools is undeniable.

Scientists whose life work is determining facts as accurately and cautiously as possible may cringe at engaging in combat on a seemingly unfair battlefield where truth and logic are not the only measures of success. But to have any impact on the political process, to make our skeptical public want to do something about our acidifying ocean, and to effectively fight skilled opponents, we must focus on what we know rather than what still remains unknown, hone subtle scientific conclusions into the simplest, most understandable points possible, state them with confidence, and get the word out using as many media outlets as possible.

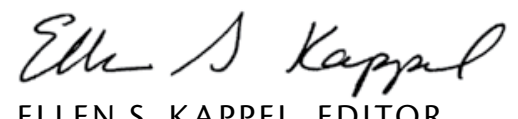

ELLEN S. KAPPEL, EDITOR 